\title{
Enterprise Asset Restructuring Related Accounting Problems and
}

\author{
Countermeasure Analysis \\ Xiao-Fang Wang $^{a}$, Dong-Dong Weng ${ }^{b}$ * \\ ${ }^{a}$ Liming Vocational University,Fujian,Quanzhou,China \\ ${ }^{\mathrm{b}}$ Quanzhou Normal University, Fujian,Quanzhou ,China \\ *Corresponding author: Dong-Dong Weng,Undergraduate,email:weng28911985@163.com
}

\begin{abstract}
Reorganization of assets can help enterprises expand the scale, improve efficiency and increase market share in the market environment, Reorganization of assets also can promote the optimization of the economic structure and spread the risk to achieve diversification, it is a important ways for enterprises to reduce the risk of delisting and solve the problems of capital and management. At the same time, China's capital market and related laws are not mature, resulting in unfair, easy to cause a variety of accounting problems in the process of asset restructuring. Through the analysis of the accounting problems of enterprise assets reorganization, I understand the problems of the current enterprise assets reorganization, and put forward the corresponding counter measures on the background and the problem.
\end{abstract}

Key words: assets reorganization; accounting problems; countermeasure analysis

\section{The reorganization of assets in the accounting issues}

\subsection{The accounting issues of corporate assets restructuring}

\subsubsection{Enterprise funds directly occupied}

In our modern process of enterprise development,enterprise assets for shareholders occupation has become particularly serious.The irrational use of funds on the other hand there is also unreasonable.Listed among China's enterprises with the parent company,there are many business contacts, so easily lead to funds being occupied and unreasonable use. On the other hand companies will use spare funds lent to the parent company,which is another way to obtain economic benefits. Therefore, the financial statements is difficult to find a large shareholder "not normal" use of corporate funds.

\subsubsection{Unequal related transactions}

In the process of enterprise assets restructuring, the association of both transactions often have different purposes,in particular transactions between the listed company and its parent company. In order to improve the business operations of the company through related party transactions,market development, business losses to reverse the situation, or to obtain the 
corresponding qualifications allocation of shares,and the resulting related party transactions will have the capital to manipulate behavior. Transactions between related parties, hides some relevant accounting information, foreign yet fully released, this incomplete information on related party transactions, the presence of some interference on the stock market funds. In China's large enterprises, mainly unequal related transactions of listed companies to turn away from their interests and obtain benefits from the listed company's related party. Between listed companies and related parties to pass the cost of sales and low prices are two basic inequalities related transactions. ${ }^{1}$ By unequal related transactions of listed companies can achieve their own interests, the company's performance and corporate financing also play a catalytic role, it also reached the purpose of corporate encroachment interests of shareholders.

\subsubsection{Behind corporate accounting functions guarantee}

In China's listed companies, many companies did not benefit from the company's long-term economic thinking, to the controlling shareholder of a large mortgage payment, this behavior is a serious violation of the principle of maximizing the interests of enterprises, affecting the development of enterprises is extremely unfavorable. If the major shareholders can not repay the debt within the prescribed time, the listed company will bear the consequences of such behavior brings with major shareholders, which would allow the development of the company into trouble. Listed companies or because of the debt problems facing financial difficulties, even in the face delisting crisis.Major shareholders of listed companies occupy capital strategy is common when a listed company can not borrow money to borrow for the purpose of a listed company to make its guarantee. At the same time, the listed companies will face a huge financial risk.

\subsubsection{Flawed accounting system and accounting standards}

Asset restructuring of the enterprise accounting system and accounting standards are still some unreasonable. For example, the presence of the development of the accounting system of the body dislocation,accounting activities practitioner management authority abuse, fuzzy accounting standards setting bodies competence.At the same time,the enterprise asset restructuring transaction process, allow serious overvaluation is widespread,resulting in corporate accounting activities faced a difficult problem to accurately determine the value of assets allowed. $^{2}$

\section{The presence of corporate accounting problems in asset reorganization reasons}

\subsection{Asset restructuring-related accounting environment is not perfect}

When companies try to avoid the valuation of assets valuation risk, while strengthening awareness of risk management and reduce the probability of occurrence of such risks.So that in the related party transactions between enterprises under a chaotic environment,coupled 
with the disclosure of related party transactions are not standardized,it is likely to cause users to understand the financial statements of accounting information related data, which led to the failure of investment, thus pose a threat to the stability of the stock market.The stock market to the development of the business brings a lot of free space,but there are many development activities are far beyond the assumptions capital accounting entity.And many companies can not be better in this regard clear boundaries, to a certain extent, affected the reorganization of assets, thus there were many accounting problems in asset reorganization venture.

\subsection{Intermediary development lag and irregularities}

In China's SMEs, the reorganization of assets is a very complex economic activity, need some agency to be able to better carry out the reorganization of assets.Similarly while some lawyers, some investment firms and accounting advisory bodies like presence management often inadequate, lack sufficient funding, the business is not enough wide range of issues. Thus, these deficiencies often lead to the authenticity of the information provided by the intermediary to the enterprise is not strong, with infidelity. ${ }^{3}$

\subsection{Flawed accounting system and guidelines}

Accounting standards of our country through the exercise of management authority of their duties, and as the accounting standards setting body, causing the body to develop the presence of non-compliant behavior.If the exercise of power through the relevant aspects of the organization will be more suitable,so as to further promote the development of accounting standards.The fair value of the overestimation in the process of restructuring transactions more common phenomenon exists,and in the process of corporate debt restructuring transactions, there is a corresponding issue of fair value judgment.

\subsection{Monetary assets accounted for transactions worth defects}

The fair value of the assets of enterprises in China's market is not very active, it is more difficult to obtain. ${ }^{4}$ Moreover, asset replacement process exists between many companies and large shareholders of related party transactions, asset evaluation at this time in the case of fair value than historical cost is very common, in essence, are manipulated in order to achieve maximum benefit. Development of this phenomenon on the fairness of the price has a huge disadvantage.

\section{To solve accounting problems asset restructuring measures}

\subsection{To ensure the independence of asset evaluation agencies}

Asset evaluation agencies should follow the standard practice of asset valuation, asset valuation in accordance with relevant state regulations, policies, and accurate data to make judgments and make recommendations valuation,with a neutral third party to provide the 
identity of the parties to the transaction fair and objective asset evaluation and assessment reports issued, the conclusions of the assessment process and the fairness of the test should accept the supervision of society and the market.Assessment agencies should substantially departing from the authorities, to society, to become a true social intermediary organizations.

\subsection{Strengthen the standardization of the assessment, make the evaluation results more credible fair}

First,we must aim at improving the level of asset evaluation agency personnel quality on this point,requiring evaluators should proceed from reality,seeking truth from facts,be carefully research to avoid during the assessment of human factors interventions disturb; assessment process should always take science adhere to the principles and methods to implement fair and equitable,it should be based on the market in order to collect information and objective facts to be expected, speculation, etc., and make the right assessment.Meanwhile, in order to make a more objective and fair assessment,asset valuation fees can not be considered to assess the value of the assets can only be developed based on workload assessment fees,and assessments should be transparent and subject to public supervision.Secondly,the assessment process should be used to assess the value of appropriate type and use the scientific method to draw a reasonable assessment of the scientific program, so that the results of asset evaluation becomes more real accuracy.In addition,different asset evaluation business,they followed the assessment procedure is different.Therefore, the assessment of business in accordance with national laws and regulations,regular assessment,and the associated assessment of the actual operation of the business,to develop reasonable and effective assessment procedures,not only to reduce assessment costs, cost savings, but also make the assessment of efficiency has been improved. Finally, from the perspective of asset valuation must develop a set of accounting with the general guidance of the assessment standards of practice, in accordance with this standard to carry out the evaluation work,and to set aside a certain flexible space for evaluate and evaluation mechanism to adapt to changing objective environment. $^{5}$

\subsection{Effectively regulate related party transaction}

In order to ensure equality of enterprise assets restructuring related party transactions, corporate assets restructuring process must strictly comply with standardized and scientific transaction guidelines, corporate accounting management system to further development and growth and innovation in the enterprise asset restructuring of related party transactions exhibited Accounting rational management,serious and systematic management of the accounting standards as the yardstick of all relevant business transactions related guidance and constraints.Establish a corporate asset accounting information quality standards for monitoring and evaluation, the first listed company to build a full sound scientific, rational and effective corporate governance structure, the majority of China's listed companies hold 
most of the shares by the shareholders of the shots, there is a veto system. Sound corporate governance structure of listed companies, in essence, that by the board of supervisors, to strengthen the strict supervision of the behavior of listed companies, in order to prevent or reduce the occurrence of illegal related-party transactions.Second,standardized related transactions,so that transactions standardization association,be sure to strengthen legislation related party transactions, and through the development of specialized specially regulations guidelines to regulate the activities of related party transactions, to ensure that the transaction is based on the guidelines for development of the market to carry out,It was trading code of conduct.Third, standardize information disclosure of related party transactions.Through the improvement of related transaction information disclosure system, the relevant provisions explicitly related reporting obligations of listed companies,increasing the transparency of related parties,minority shareholders can make fully informed business development of the listed company, in order to avoid violations of their right to know. Finally, it should be clear penalties for illegal violations of the principles and strengthen administrative law enforcement departments for the listed companies to cover up violations of regulations and other acts of hidden information in unequal related transactions Related party transactions, the need to develop a comprehensive system of punishment more perfect Program.

\subsection{Requires full disclosure of accounting information, define the scope of the disclosure}

Six principles of integrity, authenticity ,timeliness, accuracy and other accounting information quality of accounting information in the status of the most important. Information users, investors will be based on standardized information disclosure regarding prices and related restructuring and other information to make clear that the subjective decisions, it is necessary to regulate the information disclosure of related party transactions. In the Statements and notes in listed companies should disclose all information relating to, and shall not conceal, and provided false information, which choose to include the assessment mechanism, evaluation methods, pricing basis, the transfer price and book value of the difference between how much the causes for this gap and the impact of that business for the current period financial statements and the like. ${ }^{6}$

\subsection{Strengthening external supervision, the asset restructuring towards standardization}

First,strengthen the industry regulator. CPA asset reorganization is the backbone of the industry regulator, the CPA to its full social monitoring capabilities to effectively guarantee the quality of accounting information.Second,the strengthening of administrative supervision.Government,as the third hand in a market economy the regulating role in maintaining the orderly operation of the economy contributed, so external regulation of asset restructuring, improve government supervision forces imperative.Third, strengthen market supervision. Reorganization of assets is considered to be defined in some companies redefine their business scope, re-adjust the resource allocation transactions, asset restructuring 
process of its activities and the results must be completed through the market to the bridge. Therefore, strengthen market supervision is the fastest, most efficient means necessary. By adjusting the angle of regulation, efforts to improve and perfect the regulatory content, establish and improve the integrity-based information system, give full play to the positive role of the market, the government, effectively regulate asset restructuring activities, restructuring to improve efficiency.

\subsection{Improve the relevant accounting standards, accounting system}

Improve the quality of accounting information disclosure and ensure transparency of information is increasing, we must continue to improve and perfect the relevant accounting system accounting standards, including asset transfer pricing, the book value of estimated asset evaluation system, etc., and, in a sound and comprehensive accounting system accounting process guidelines should also strengthen asset activity illegal conduct penalties, and constantly improve and perfect the system of related party transactions and the full disclosure of accounting information system, the complete elimination of the virtual reorganization, mergers and false behavior, from accounting to improve enterprise management system to ensure that corporate assets up benefit restructuring halt institutional asset reorganization of accounting information distortion phenomenon.

\section{References}

1. M. Wei, Enterprise asset restructuring related accounting issues [J]. China foreign investment, 2011, No.24817:46+48.

2. X. H. Qu, J. Xiao, Company asset replacement changes of financial performance characteristics and measurement attribute specification implementation effect [J]. Accounting research, 2009, No.05:38-45+96-97.

3. Y.C. Song, Research on some accounting problems of asset reorganization [J]. financial and economic circles (Academic Edition), 2015, No.37211:280-281.

4. H.J. Wang, study asset restructuring of modern enterprise accounting issues of [J]. Chinese and foreign entrepreneurs, 2015, No.51836:47.

5. W.J. Cui, Wang Ping, Research on accounting problems of enterprise asset reorganization [J]. shopping mall modernization, 2015 (11)

6. C.L. Zhang, The purpose of the enterprise assets reorganization and the analysis of the existing problems of the [J]. market modernization, 2014, No.76122:246-247. 